\title{
Aprendizagem Baseada em Equipes (Team-Based Learning): um método ativo para o Ensino de Física ${ }^{+*}$
}

Tobias Espinosa de Oliveiral

Doutorando em Ensino de Física

Universidade Federal do Rio Grande do Sul

Ives Solano Araujo ${ }^{2}$

Eliane Angela Veit $^{3}$

Instituto de Física - Universidade Federal do Rio Grande do Sul

Porto Alegre - RS

\section{Resumo}

O método tradicional de ensino, caracterizado basicamente por aulas expositivas centradas no professor e pela resolução de longas listas de exercícios como atividade de fixação dos conteúdos, é ainda presente em grande parte das aulas de Física em nível médio e superior, apesar de sua baixa eficiência. $O$ uso de tal método é um dos fatores que pode contribuir para agravar os altos índices de reprovação, abandono e desmotivação do aluno, o que denota a importância de repensarmos sua prática. Diversos métodos ativos de ensino têm mostrado resultados positivos, principalmente, no que diz respeito à aprendizagem de conteúdos e a construção de habilidades, contudo ainda mostram-se pouco conhecidos pelos professores de Física brasileiros. O propósito deste artigo é apresentar um destes métodos, o Team-Based Learning (TBL), ou Aprendizagem Baseada em Equipes, que vem sendo empregado com sucesso em cursos da área de Ciências da Saúde e Administração em universidades norte americanas, mas ainda pouco difundido no ensino de Ciências Naturais. $O$ TBL busca melhorar os resultados de aprendizagem e desenvolver habili-

\footnotetext{
${ }^{+}$Team-Based Learning: an active teaching method for Physics Education

* Recebido: setembro de 2015.

Aceito: agosto de 2016.

1 E-mail: tobias.espinosa@ufrgs.br

2 E-mail: ives@if.ufrgs.br

${ }^{3}$ E-mail: eav@if.ufrgs.br
} 
dades de trabalho colaborativo através de atividades de preparação prévia, resolução de problemas (individualmente e em pequenos grupos), entre outras estratégias. No presente artigo, descrevemos em detalhe o método e apresentamos os principais resultados da escassa literatura de seu emprego no ensino de Física.

Palavras-chave: Aprendizagem Baseada em Equipes; Team-Based Learning; Ensino de Física; TBL.

\begin{abstract}
Traditional teacher-centered methods, characterized by lecturing and resolution of a huge number of exercises as content fixation activities, are still omnipresent in physics classes from high school to college level, even though the efficiency of this method is low. Such methods contribute, among many others factors, such as social, economic and cultural, to high rates of failure, dropout and demotivation of the students, which denotes the importance to rethink about this practice. Several active teaching methods have shown positive results regarding the learning of contents and skills building by the students. However, these methodologies are mostly unknown by Physics teachers in Brazil. The purpose of this paper is to present one of these methods, the Team-Based Learning (TBL), which is highly widespread in health and business courses in North American Universities. It aims to improve learning and develop collaborative skills through preparatory activities, problem solving (individually and in small groups), among other strategies. In this paper, we describe in detail the method and present the main results of the scarce literature in Physics Education.
\end{abstract}

Keywords: Team-Based Learning; Physics Education; TBL.

\title{
I. Introdução
}

Comumente encontramos, em todos os níveis de ensino, salas de aula com estudantes que adotam uma postura passiva, com pouca participação em discussões sobre o conteúdo. A esse cenário estão associados os métodos de ensino tradicionais, caracterizado por aulas expositivas, centradas no professor, e alunos que seguem estratégias como: estudo por memorização centralizado nas notas; compartimentação do conhecimento; trabalho individual; e busca pelo entendimento (ou adivinhação) da visão de mundo do professor, em vez de refletirem sobre o 
seu próprio (BARROS et al., 2004). As atividades discentes muitas vezes se resumem à resolução de longas listas de exercícios, normalmente extraídas do livro-texto adotado. Ainda que não tenham alcançado uma compreensão conceitual adequada sobre o conteúdo em estudo, os estudantes podem lograr bons resultados em provas e exames, que costumam ser a única forma de avaliação (somativa) utilizada nas disciplinas e se limitam, em boa parte, à resolução de exercícios similares aos das listas.

Ainda assim, altos índices de reprovação e abandono são observados (e.g. BARROSO et al., 2003; PASSOS et al., 2007; LIMA JUNIOR, 2013). Evidentemente, o problema da evasão e reprovação não é causado unicamente pela dinâmica adotada em sala de aula. Vários outros fatores, sociais, culturais e econômicos, são relevantes. Contudo, a modificação do método de ensino por parte do professor pode estar ao alcance de docentes que se veem, de outra forma, impotentes diante da falta de perspectiva de mudança do cenário educacional brasileiro no curto prazo.

Como exemplo da influência de fatores culturais e socioeconômicos sobre o fenômeno da evasão, Lima Junior, Ostermann e Rezende (2012) mostram, por meio de uma análise interpretativa à luz da sociologia da educação de Bourdieu, que estudantes de diferentes origens sociais, ou seja, com capitais econômicos e culturais distintos, ao ingressarem no curso de Física, possuem aproximadamente as mesmas chances de concluírem a graduação. Em contrapartida, verificaram também que dentre os alunos que se formam no curso de Física, aqueles com origem social mais humilde demoram mais tempo para concluir o curso. Os resultados encontrados por tais autores demonstram que o problema da evasão em cursos de Física ultrapassa os limites da sala de aula.

Por outro lado, no entanto, tem sido mostrado que métodos ativos de ensino têm contribuído para diminuir a reprovação e evasão (e.g. LASRY; MAZUR; WATKINS, 2008; WATKINS; MAZUR, 2013) e com o favorecimento de minorias (e.g. LORENZO; CROUCH; MAZUR, 2006; BREWE et al., 2010).

Uma alternativa nesse sentido, que tem despertado atenção de professores e pesquisadores, é a "inversão" das aulas em relação às tradicionais no que diz respeito: (i) ao foco do processo de ensino, que passa a ser centrado no aluno ao invés do professor e (ii) ao primeiro contato do discente com o conteúdo a ser estudado. Este contato ocorre previamente em casa, priorizando o tempo em sala de aula para dirimir dúvidas e resolver problemas com os colegas, em contraposição ao tradicional, em que é em sala de aula que o aluno se depara com o conhecimento a ser estudado e depois, sozinho em casa, se dedica à solução de exercícios e problemas (BERGMANN; SAMS, 2012).

No contexto do ensino de Física, existem vários trabalhos que corroboram a ideia de que o ensino ativo promove, entre outros benefícios, uma melhor aprendizagem conceitual (e.g. BEICHNER et al., 2007; HAKE, 1998; CROUCH; MAZUR, 2001; BARROS et al., 2004; RUDOLPH et al., 2014). 
Como exemplos de métodos que podem ser utilizados em metodologias ativas de ensino, pode-se citar: One-Minute Paper (STEAD, 2005); Think-Pair-Share (LYMAN, 1981, 1987); Problem-Based Learning (BARROWS; TAMBLYN, 1980; DUCH, 1996); Ensino por Investigação (CARVALHO, 2013); Team-Based Learning (MICHAELSEN; KNIGHT; FINK, 2004); entre outros.

Dentre os diferentes métodos, o Peer Instruction (MAZUR, 1997) e o Just-in-Time Teaching ${ }^{4}$ (NOVAK, 1999) têm sido abordados em trabalhos nacionais recentemente (ARAUJO; MAZUR, 2013; MÜLLER et al., 2012; OLIVEIRA; VEIT; ARAUJO, 2015).

Os métodos Peer Instruction e Just-in-Time Teaching, em uma tradução livre Instrução pelos Colegas e Ensino sob Medida (ARAUJO; MAZUR, 2013), visam, especialmente, a aprendizagem conceitual. No entanto, no ensino de Física, espera-se que os alunos também resolvam problemas e o domínio conceitual é uma condição necessária, mas não suficiente, para a resolução deles (SILVEIRA; MOREIRA; AXT, 1992).

O trabalho em pequenos grupos em sala de aula, ao propiciar um processo de argumentação e de contato com diferentes percepções, pode conduzir a um melhor entendimento dos conteúdos abordados. Heller $(1992 ; 1999)$ destaca que, em atividades em grupo, os alunos são capazes de resolver problemas mais complexos e que, além disso, as soluções encontradas são significativamente melhores do que aquelas produzidas individualmente pelo melhor membro do grupo, principalmente no que diz respeito à análise qualitativa. Adicionalmente, o trabalho em grupo favorece o ensino do conteúdo, a comunicação entre os estudantes e entre professor e alunos, bem como alguns aspectos subjetivos necessários para o convívio em sociedade. Nessa perspectiva, um método que favoreça a resolução de problemas por meio de trabalho em grupo é bem-vindo.

O objetivo central do presente artigo é apresentar o método Team-Based Learning (TBL), ou Aprendizagem Baseada em Equipes, em uma tradução livre, a fim de familiarizar os professores brasileiros com uma proposta metodológica que favorece a interação social dos alunos em sala de aula. O TBL (MICHAELSEN, 2004) tem como foco melhorar a aprendizagem de conteúdos e desenvolver habilidades de trabalho colaborativo através de uma estrutura que envolve, entre outras atividades, resolução de problemas. Os alunos se envolvem em atividades de preparação individual e em equipe, que consistem em estudo prévio extraclasse; resolução de questões conceituais em sala de aula; e realização de tarefas de aplicação dos conceitos (resolução de problemas em equipe), também em classe. Para auxiliar no desenvolvimento das equipes, elas são estrategicamente montadas pelo professor e fixas, ou seja, é mantida a mesma formação das equipes durante a aplicação do método. Os alunos têm a possibilidade de avaliar

\footnotetext{
${ }^{4}$ O método Just-in-Time Teaching, ou Ensino sob Medida, consiste em: (i) estudo prévio (leitura de algum capítulo de livro, por exemplo), (ii) questões conceituais pós-leitura, respondidas ainda antes de ir para a aula, para verificar o entendimento do assunto lido e uma pergunta onde indaga-se o aluno sobre o entendimento daquilo que foi lido, seguido de (iii) uma aula onde o professor foca nas principais dúvidas que os estudantes tiveram durante a leitura do texto, ou seja, um ensino sob medida para os estudantes (ARAUJO; MAZUR, 2013; OLIVEIRA; VEIT; ARAUJO, 2015).
} 
seus colegas de equipe em determinados momentos ao longo do trabalho. O TBL foi utilizado pelos autores do presente artigo em uma disciplina de Física Geral em uma universidade brasileira (OLIVEIRA, 2016). Não temos como objetivo aqui discutir tais resultados, mas divulgar para a comunidade um método que tem potencial para mudar a dinâmica da sala de aula de Física, como dão indícios os (ainda poucos) trabalhos na área (ibid.; DEANTONIO et al., 2007; METOYER et al., 2009; PARDAMEAN et al., 2014; PARAPPILLY; SCHMIDT; RITTER, 2015).

Apesar de pouco explorado no ensino de Física, o TBL se mostra eficaz em outras áreas, especialmente nas Ciências da Saúde, como apresentaremos na Seção 3. Na Seção 2, apresentamos detalhadamente o TBL, especificando, nas subseções 2.1 a 2.4, os quatro fundamentos do método, a saber: a formação das equipes; as atividades de ensino (preparação e a aplicação); e as avaliações. Em seguida, na Seção 3, expomos uma breve revisão da literatura sobre o TBL no ensino de Física. Na Seção 4, propomos algumas considerações gerais sobre o TBL e apontamos possíveis perspectivas para pesquisas e ensino envolvendo tal método.

\section{Team-Based Learning (TBL)}

O TBL foi criado pelo professor de gestão e negócios Larry Michaelsen, no final dos anos 70, na Universidade de Oklahoma (EUA). O método tem como foco melhorar a aprendizagem e desenvolver habilidades de trabalho colaborativo, através de uma estrutura que envolve: o gerenciamento de equipes de aprendizagem, tarefas de preparação e aplicação de conceitos, feedback constante e avaliação entre os colegas. A ideia central é que os alunos se sintam responsáveis pela própria aprendizagem e pela dos colegas (MICHAELSEN, KNIGHT; FINK, 2004).

Na implementação do TBL, uma disciplina é estruturada em módulos, cujas principais fases são apresentadas na Fig. 1, que passamos a expor. Cada módulo é dividido em duas partes principais, envolvendo atividades de preparação e aplicação, tanto extraclasse quanto em sala de aula (MICHAELSEN, 2004).

Iniciando a fase de preparação (quadro 1 da Fig. 1), os estudantes realizam um estudo prévio extraclasse, de caráter preparatório ao que será abordado em aula. Os materiais para estudo podem ser constituídos por textos, vídeos, simulações computacionais etc. e são usualmente entregues aos alunos com antecedência mínima de dois dias.

Em sala de aula (quadro 2 da Fig. 1), dando sequência à preparação, os alunos respondem um teste conceitual individual (Teste de Preparação individual - TPi) relacionado com o estudo realizado na fase de preparação extraclasse. Suas respostas são recolhidas pelo docente. Logo após, o mesmo teste é realizado em equipe (Teste de Preparação em equipe - TPe). Nessa fase, os alunos dialogam com os colegas de equipe e recebem uma cartela contendo uma grade para marcar as respostas da equipe, definidas consensualmente. $\mathrm{O}$ processo de marcação de 
respostas é similar ao usado em bilhetes de premiação instantânea, conhecidos como "raspadinhas". A resposta considerada certa pela equipe é marcada na grade raspando o material que cobre a alternativa escolhida. Se a resposta estiver correta, aparecerá o símbolo de uma estrela.

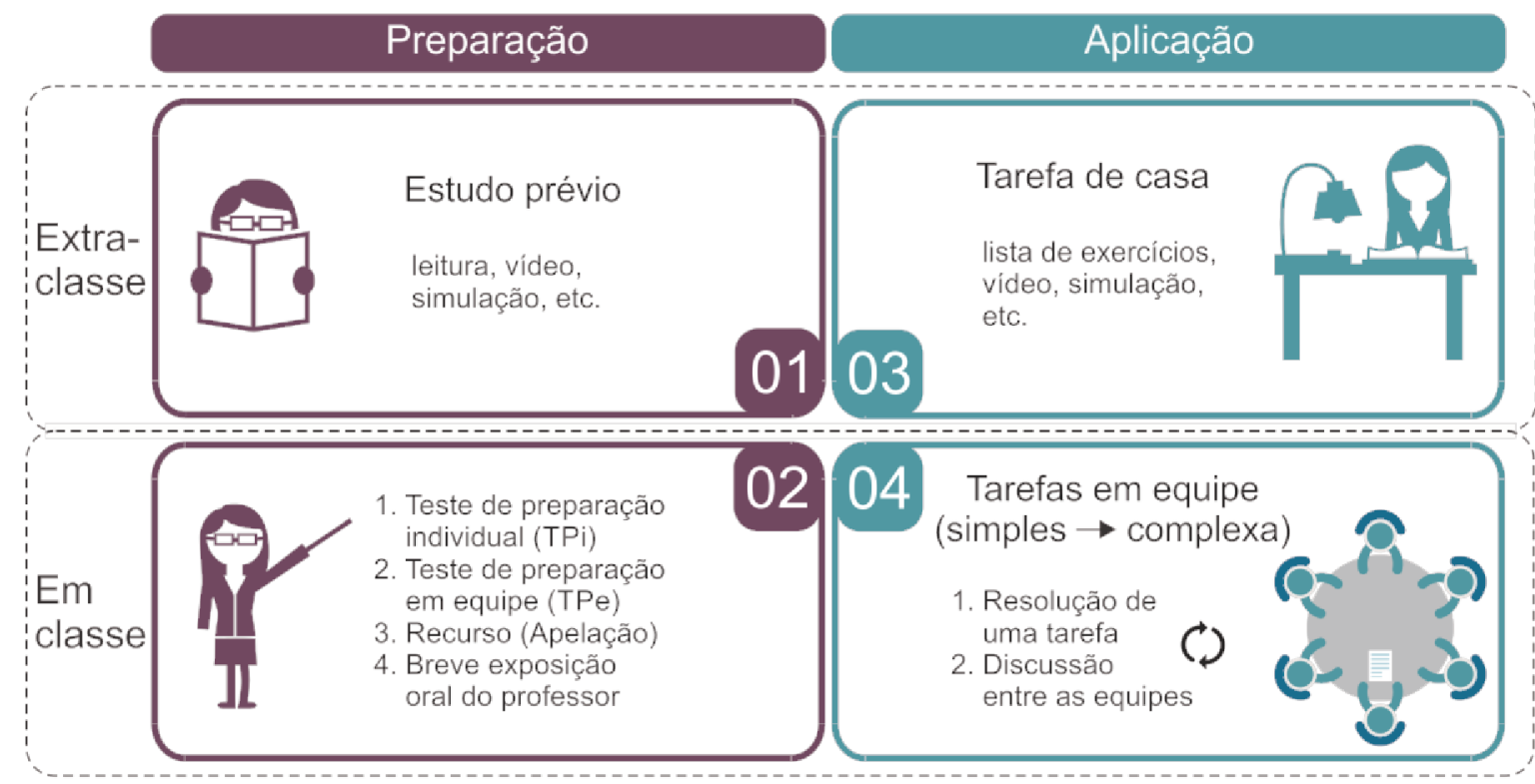

Fig. 1 - Principais fases de cada módulo do TBL (OLIVEIRA, 2016).

Em caso de erro, os alunos voltam a discutir para tentar encontrar a resposta correta, escolhendo, então, outra alternativa para raspar. Em seguida, caso tenham alguma objeção à questão ou à sua correção, podem apresentar um recurso (ou apelação), que o professor pode julgar imediatamente após sua formulação ou em um momento posterior. A fase de preparação termina com o professor fazendo uma exposição oral sobre pontos referentes às dificuldades mais frequentes apresentadas pelos alunos.

Depois que os principais conceitos do módulo são discutidos, as equipes se envolvem em tarefas de aplicação (não necessariamente na mesma aula) que vão gradualmente se tornando mais complexas, e são intercaladas com tarefas individuais (quadro 3 da Figura 1) a serem feitas fora da sala de aula (fase de aplicação). As tarefas realizadas em sala de aula (quadro 4 da Figura 1) geralmente são do tipo "resolução de problemas". Todas as equipes resolvem o mesmo problema, um por vez e, ao final de cada solução, expõem suas respostas (em pequenos quadros brancos, por exemplo), discutindo entre elas e com o professor. Ao final de cada discussão, o professor entrega um novo problema. As duas fases (preparação e aplicação) serão explicadas detalhadamente em subseções posteriores.

Alguns trabalhos na literatura (e.g. MICHAELSEN; SWEET, 2011; FINK, 2004) sugerem repetições cíclicas de cinco a sete módulos. Porém, o número de repetições varia dependendo da quantidade de horas e de encontros semanais oferecidos pela disciplina, além de certa diferenciação de conteúdo e complexidade. 
Além da dinâmica descrita anteriormente, para que o processo dê resultados positivos, em termos de aprendizagem e trabalho colaborativo, é importante que o professor gerencie a formação das equipes e conduza avaliações individuais, em equipe e entre os membros da equipe. São quatro os elementos essenciais para a utilização do TBL (MICHAELSEN; SWEET, 2011) que serão discutidos nas seções seguintes: (i) formação das equipes; (ii) atividades da fase de preparação; (iii) atividades da fase de aplicação; e (iv) avaliações.

\section{II.1 Formação das equipes}

Grupos e equipes são conceitos distintos no contexto do TBL. Toda equipe pode ser chamada de grupo, mas nem todo grupo é uma equipe. Segundo Fink (2004) equipes se diferenciam de grupos, principalmente, por duas características: (i) alto nível de comprometimento individual para o bom rendimento do grupo e (ii) confiança entre os membros. O aparecimento dessas características demanda tempo de interação; uma tarefa desafiadora que se torna um objetivo comum; e feedback ${ }^{5}$ tanto do trabalho individual quanto de equipe (FINK, 2004). Oakley, Felder e Brent (2004) também argumentam a favor das equipes de aprendizagem, dizendo que se diferenciam dos grupos porque os membros sempre trabalham juntos, assumem diferentes papéis e responsabilidades, ajudam uns aos outros sempre que possível e resolvem conflitos amigavelmente, entre outros fatores. O desenvolvimento das equipes ocorre pela ascensão (ou pelo surgimento) dessas características. Segundo Watson, Michaelsen e Sharp (1991) em 98\% dos casos, o desempenho da equipe, em um teste padronizado aplicado pelos autores, supera o desempenho individual do melhor membro da equipe.

As equipes são compostas por cinco a sete alunos e são organizadas pelo professor, que procura montar equipes heterogêneas em relação ao conhecimento, experiências pessoais e/ou profissionais, interesses, entre outros fatores, favorecendo o surgimento de equipes com níveis semelhantes de interatividade. Por exemplo, se alguma equipe é formada apenas com alunos tímidos ou o contrário, apenas com alunos extrovertidos, a tendência é que, no primeiro caso, o diálogo entre os membros seja prejudicado e, no segundo, a conversa pode ser tanta que acabe se tornando dispersiva. Oakley, Felder e Brent (2004) destacam que equipes formadas apenas por alunos com mais facilidade de aprendizagem, ou compostas tão somente por aqueles que têm mais dificuldade, não funcionam. No caso de equipes com maior facilidade, os estudantes simplesmente resolvem as atividades quase que individualmente e não as discutem. As equipes formadas apenas com estudantes com dificuldades acabam por reforçar o uso de con-

\footnotetext{
${ }^{5}$ Hattie e Timperley (2007) conceitualizam feedback como sendo uma informação dada por um agente (professor ou colega, por exemplo) em relação à sua compreensão. Os autores fazem questão de destacar que o foco dado à feedback não está baseado em um modelo behaviorista de input-output. Pelo contrário, o feedback está centrado nas informações sobre o conteúdo e nas construções que os alunos fazem durante o processo de aprendizagem. $\mathrm{O}$ feedback não é necessariamente um reforço, pois não precisa ser aceito, e não é responsável, por si só, pelo início de uma nova ação, podendo ser alterado ou negado. Eles afirmam que o feedback está entre as influências mais importantes sobre a aprendizagem dos estudantes.
} 
ceitos aprendidos erroneamente. Ou seja, a diversidade beneficia os alunos avançados que podem potencializar a sua aprendizagem ensinando, e também auxilia àqueles com dificuldade, que aprendem com seus colegas e agregam à discussão entre os membros da equipe.

Oakley, Felder e Brent (ibid.) também argumentam que grupos definidos pelos próprios estudantes são mais propensos a não seguir (ou mesmo sabotar) a proposta de trabalho. Esses autores também chamam atenção para problemas que o professor pode enfrentar por não deixar que os alunos formem suas próprias equipes de trabalho. Alguns estudantes podem ficar insatisfeitos com isto e, por consequência, gerar uma barreira entre os estudantes e o professor antes mesmo do início da disciplina. Para diminuir esse problema, o professor tenta conquistar os alunos, explicando-lhes os benefícios de tal escolha, mostrando os aspectos positivos que a constituição heterogênea das equipes trará para a aprendizagem; também pode argumentar sobre a futura (ou atual) vida profissional dos estudantes, na qual independentemente da profissão e local de trabalho (pesquisa, escola, empresa), eles não terão a opção de escolher seus colegas e, mesmo assim, terão que aprender a trabalhar de forma colaborativa. Nanes (2013) afirma que a ideia inicial de muitos estudantes, de que trabalham melhor individualmente, diminui significativamente após algumas semanas de uso do TBL.

As equipes devem ser permanentes. Diferentemente de outros métodos que utilizam pequenos grupos apenas esporadicamente, no TBL as equipes são pensadas para trabalharem em longo prazo, com isso, os estudantes tornam-se capazes de ampliar suas capacidades sociais e intelectuais (MICHAELSEN; SWEET; PARMELEE, 2008).

Para separar as equipes, é recomendado que o professor aplique, no primeiro dia de aula, um questionário com perguntas pessoais e sobre a sua formação para poder torná-las as mais heterogêneas possíveis. Por exemplo: "por que você está fazendo este curso?"; "quais suas impressões sobre o trabalho em grupo 6 ?"; "tem algo sobre você que é, provavelmente, um diferencial perante os demais colegas? (pode ser algo como um hobby, alguma habilidade ou interesse)". Dependendo do contexto, diferentes perguntas podem ser feitas. Outro ponto interessante é que alguns alunos se sentem valorizados, pois notam que o professor está interessado na individualidade de cada um (OAKLEY; FELDER; BRENT, 2004).

No caso de uma disciplina de Física, são adequadas algumas questões que investiguem as crenças, atitudes e dificuldades na área, como por exemplo: "você possui alguma dificuldade para aprender Física?"; "você tem mais afinidade em que área da Física? (Física teórica, Física experimental, ensino de Física, etc.)". O questionário pode ser feito online (usando o Google Forms ${ }^{7}$, por exemplo) para que os alunos possam responder fora da sala de aula. Um exemplo de questionário é apresentado no Apêndice A.

\footnotetext{
${ }^{6}$ No questionário, usa-se o termo "trabalho em grupo" devido à familiaridade dos alunos com o conceito de grupo, em comparação com o de equipe.

${ }^{7}$ O Google Forms é uma ferramenta gratuita que permite criar formulários e disponibilizá-los online para que possam ser respondidos. As respostas são organizadas em tabelas, as quais o autor do formulário tem acesso. Disponível em: $<\underline{\text { http://docs.google.com }>\text {. }}$
} 


\section{II.2 Fase de Preparação}

$\mathrm{Na}$ fase de preparação ${ }^{8}$, os alunos realizam inicialmente um Estudo Prévio, extraclasse, de algum material recomendado pelo professor. Essa atividade preparatória pode ser a leitura de um texto, capítulo de livro, artigo científico, página da internet, além de recomendações para assistir vídeos ou explorar simulações interativas. Essa tarefa envolve os principais conceitos do conteúdo. Ao estudá-los os alunos estarão, em parte, preparados para auxiliar sua equipe na fase de aplicação.

Após a realização dessa atividade, eles passam por um Teste de Preparação individual $^{9}$ (TPi) em sala de aula. O teste é composto por algumas questões de múltipla escolha sobre conceitos fundamentais do módulo de estudo (um exemplo de questão conceitual é mostrado na Fig. 2). Recomenda-se solicitar que os alunos escrevam uma breve justificativa para cada questão do teste, a qual pode ser avaliada em termos do raciocínio demonstrado pelo aluno para realizá-la. O fundamental não é que o aluno dê a resposta cientificamente correta, mas que ele demonstre ter se engajado para resolver a questão.

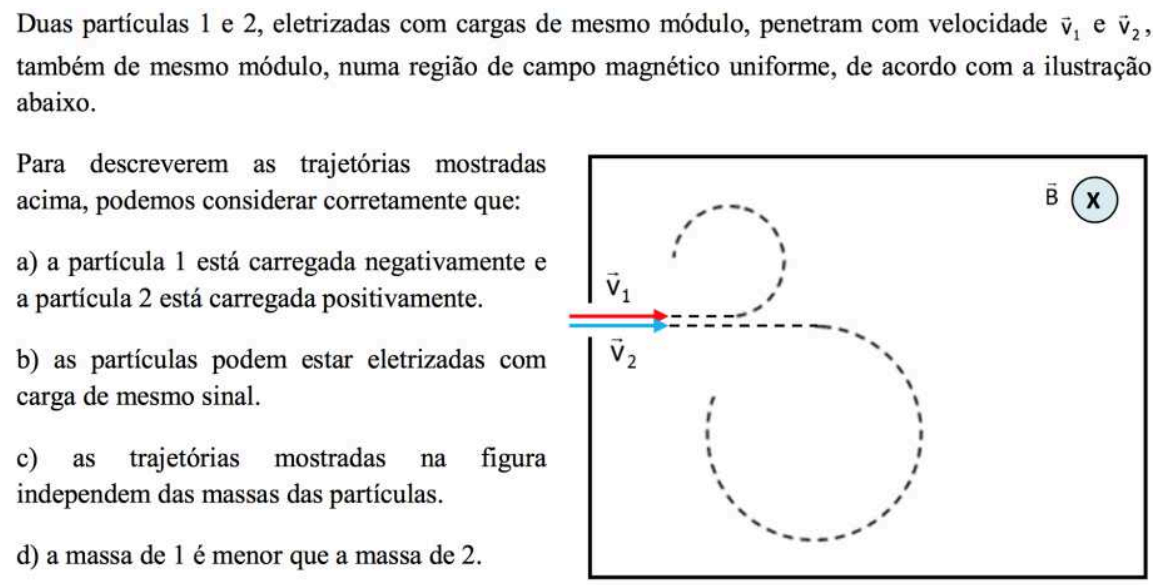

Fig. 2 - Ilustração de uma questão conceitual (OLIVEIRA; VEIT; ARAUJO, 2015) ${ }^{10}$.

Em seguida, é aplicado o Teste de Preparação em equipe ${ }^{11}$ (TPe), que é idêntico ao teste individual, porém a ser respondido pela equipe. Os estudantes recebem um feedback imediato da resposta de cada uma das questões, só passando para a questão seguinte depois de terem entrado em consenso com a equipe sobre a questão em pauta. A ideia é que como os estudantes

\footnotetext{
8 Originalmente, a fase de preparação é conhecida pela sigla RAP (Readiness Assurance Process - processo de garantia de preparação). Optamos, para simplificar, por utilizar apenas a nomenclatura preparação.

${ }^{9} \mathrm{O}$ termo é conhecido como iRAT (individual Readiness Assurance Test - teste individual de garantia de preparação).

10 Outras questões conceituais de Oliveira, Veit e Araujo (2015) estão disponíveis em: <http://lief.if.ufrgs.br/pub/cref/n27_Oliveira/testes_conceituais.pdf>

${ }^{11}$ Comumente chamado de tRAT (team Readiness Assurance Test - teste em equipe de garantia de preparação).
} 
já pensaram sobre as questões no TPi, as discussões são mais produtivas no TPe e, assim, os próprios colegas colaboram entre si para sanar as dúvidas remanescentes do TPi.

O processo de feedback é feito por meio de Cartões de Correção Instantânea (CCI), comumente chamados de "raspadinhas"12" (Fig. 3). Nos cartões, a alternativa correta é indicada pelo símbolo "estrela". Se os alunos rasparem e não encontrarem a estrela, voltam a discutir a questão. A avaliação pode ser feita pelo acerto das respostas. No caso de cinco alternativas, por exemplo, se os alunos acertarem na primeira tentativa, a equipe recebe quatro pontos na questão (pontuação correspondente ao número de retângulos não raspados), se acertarem na segunda tentativa, recebem três pontos e assim sucessivamente. Se todas as alternativas de resposta para uma determinada questão forem raspadas, a equipe não pontua.

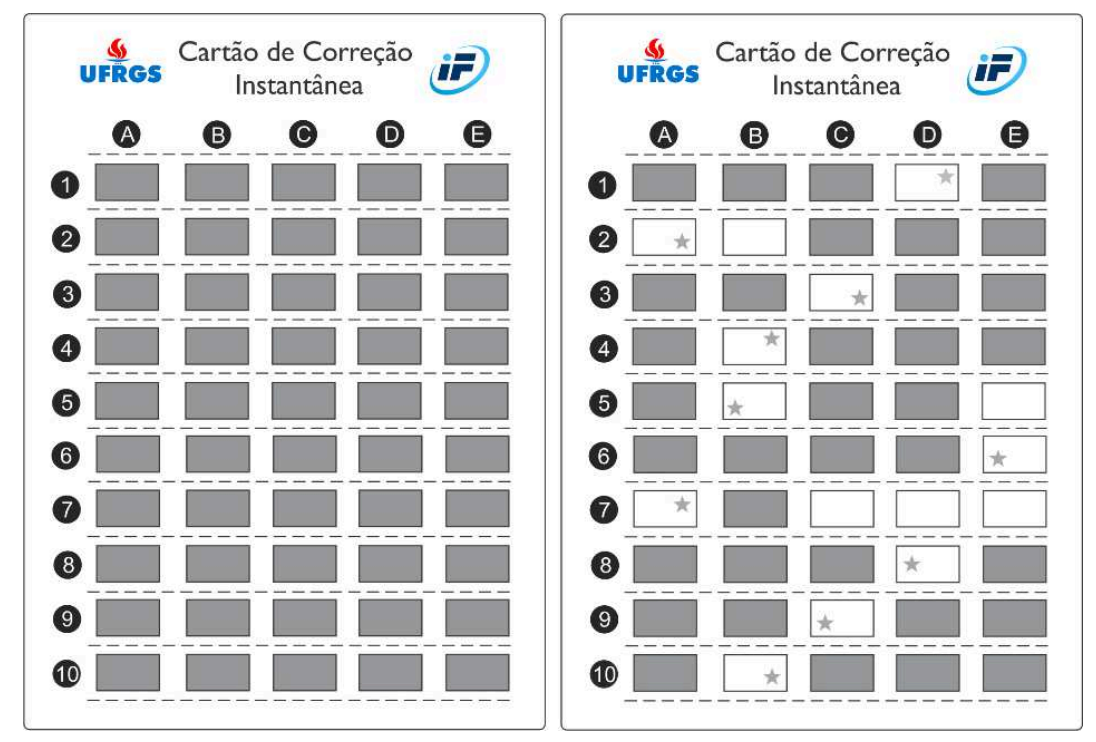

Fig. 3 - Cartão de Correção Instantânea. A resposta correta é sinalizada por uma estrela.

Cotner, Baepler e Kellerman (2008) fizeram um estudo sobre o uso do CCI com atividades em grupo e avaliaram as atitudes dos alunos perante sua utilização. Constataram que essa técnica encoraja a participação, dinamiza as discussões e ajuda os alunos a identificarem as suas dificuldades, entre outros fatores positivos. Em sua maioria, os alunos estudados aprovaram as atividades em grupo com a utilização do CCI e afirmaram que a técnica os auxiliou a revelar aspectos não compreendidos e a alcançar melhores desempenhos em testes. Em uma aplicação realizada em uma disciplina introdutória de eletromagnetismo na Universidade Federal do Rio Grande do Sul (UFRGS), os estudantes mostraram-se favoráveis à técnica por estimular a discussão entre os colegas (OLIVEIRA, 2016).

\footnotetext{
12 A versão original é chamada de IF-AT (Immediate Feedback Assessment Technique - Técnica de Avaliação com Feedback Imediato - http://www.epsteineducation.com). Esses cartões podem ser confeccionados de modo caseiro. Uma rápida busca em um motor de busca como o Google, o leitor pode encontrar diferentes maneiras de confeccioná-los.
} 
Após as atividades com os cartões, os alunos têm a oportunidade de interpor um Recurso verbal ou escrito justificando porque acreditam que a correção ou formulação da questão está incorreta. O professor pode julgá-lo no instante em que o recurso é apresentado, ou em momento posterior. Por fim, o professor faz uma Breve Exposição Oral com as principais ideias trabalhadas, esclarecendo aspectos relacionados às maiores dificuldades dos alunos identificadas durante as tarefas de preparação.

Resumidamente, a fase de preparação envolve as seguintes atividades por parte dos alunos: (i) estudar previamente o conteúdo de forma individual (fora da sala de aula); (ii) responder, em sala de aula, a um teste individual; (iii) responder o mesmo teste, agora em equipe, obtendo feedback imediato sobre a correção de suas escolhas; (iv) apresentar recursos ao professor, em caso de discordância sobre a correção das respostas; (v) assistir uma breve exposição do professor, no qual são realçados os pontos essenciais para resolução das questões conceituais apresentadas e o esclarecimento de dúvidas sobre o conteúdo que tenham surgido ao longo do processo.

\section{II.3 Fase de aplicação}

A segunda fase, Aplicação, apresenta uma sequência de Tarefas em Equipe que vão gradualmente se tornando mais complexas. Fora da sala de aula, os alunos trabalham individualmente em atividades de aplicação mais simples que as tarefas que farão em equipe em sala de aula. As tarefas realizadas em sala buscam promover interações entre os alunos e espírito de equipe. Para isso, as tarefas não podem ser muito simples, pois assim não promoveriam a troca de opiniões entre os membros da equipe, nem complexas demais, de maneira que os estudantes não consigam se envolver na atividade. A critério do professor, podem envolver, além de resolução de problemas convencionais, desenvolvimento de projetos, atividades computacionais (de simulação ou modelagem) e experimentais, bem como problemas de tomada de decisão. Nesse tipo de problema, os alunos são solicitados a usarem o conhecimento adquirido para se posicionarem a respeito de uma questão. Um exemplo desse tipo de atividade é o júri simulado, que vem sendo utilizado no ensino de Física (e.g. SILVA; MARTINS, 2009; VIEIRA; MELO; BERNARDO, 2014).

Para guiar as atividades da fase de aplicação, recomenda-se seguir quatro princípios ${ }^{13}$ (MICHAELSEN, 2004):

(i) problema significativo: a tarefa proposta precisa ser significativa, no sentido de instigar o engajamento cognitivo dos estudantes. Para isso, é importante que a solução exija a aplicação de conceitos anteriormente aprendidos. Problemas contextualizados também podem contribuir para o engajamento dos alunos.

(ii) mesmo problema: todas as equipes trabalham no mesmo problema, um por vez, possibilitando, ao final de cada problema, a discussão e a análise de diferentes soluções.

\footnotetext{
13 Em inglês, os quatro princípios são conhecidos como "4S's: Significant Problems, Same Problem, Specific Choice e Simultaneous Report”. Infelizmente, em português não contamos com tal harmonia.
} 
(iii) escolha específica: as tarefas precisam conter uma escolha (ou resposta) específica. É extremamente importante, na aplicação do TBL, a discussão entre as equipes e para isso os problemas devem levar a uma escolha específica. Isso não significa dizer que as tarefas precisam ser de múltipla escolha.

(iv) relato simultâneo: o relato das respostas entre as equipes acontece de forma simultânea. A solução dos problemas deve ser acompanhada de discussão entre as equipes, propiciando um feedback por parte do professor e dos colegas ao término de cada tarefa.

Sweet, Michaelsen e Wright (2008) sugerem que os alunos, antes de reportarem suas respostas, escrevam uma justificativa. Isso facilita a argumentação no momento do debate. Os autores destacam algumas maneiras para a declaração simultânea de respostas: as mais comuns são a utilização de flashcards (cartões de respostas) ou clickers (dispositivos eletrônicos que computam as respostas para o professor). No caso de respostas mais complexas pode-se utilizar um sistema de Exposição de Respostas (The Galery Walk). Nesse caso, as equipes podem expor seus resultados e soluções em pequenos quadros brancos (JACKSON; DUKERICH; HESTENES, 2008), papéis ou apresentações de slides feitas no computador, e, com o uso dessas ferramentas, fazer pequenas explanações, ou simplesmente expor os trabalhos, enquanto os colegas e o professor fazem sugestões e críticas. Esse método é útil, no caso do uso de mapas conceituais, deduções de equações e resolução de problemas, demonstrações experimentais e simulações computacionais.

A seguir mostramos um exemplo de problema contextualizado utilizado na fase de aplicação em uma disciplina introdutória de eletromagnetismo.

Você foi convidado para trabalhar, durante um intercâmbio de férias, em uma companhia telefônica, na Califórnia. Durante um recente terremoto, uma longa linha telefônica subterrânea de 1,0 km foi esmagada em algum ponto. Essa linha é constituída por dois fios de cobre paralelos de mesmo diâmetro e comprimento, que normalmente não estão conectados. No local onde a linha foi esmagada, os dois fios fazem contato. Seu chefe quer que você encontre esse lugar, assim o fio pode ser desenterrado e consertado. Então, você desliga a linha telefônica desconectando ambos os fios nas duas extremidades. Em seguida, você vai até uma das extremidades e conecta um terminal da bateria a um fio e o outro terminal a um amperímetro (que podemos considerar com resistência nula). Quando o outro terminal do amperímetro é ligado ao outro fio, o amperímetro mostra uma corrente de 1 A. Você então desliga tudo e viaja para a outra extremidade, repetindo o processo a corrente encontrada é de $1 / 3 \mathrm{~A}^{14}$.

\section{II.4 As avaliações}

Em uma aula tradicional, os estudantes possuem, quase exclusivamente, responsabilidades com o professor, ou seja, os alunos estudam para atender as expectativas do professor e,

\footnotetext{
${ }^{14}$ Problema traduzido e adaptado do arquivo online de problemas contextualmente ricos da Universidade do Minnesota <http://groups.physics.umn.edu/physed/>.
} 
assim são avaliados especialmente por provas. O TBL instiga que eles sejam responsáveis por se prepararem individualmente para a aula e em contribuir com seus colegas de equipe.

Se os alunos não se preparam, deixando de realizar as atividades propostas pelo professor na fase de preparação, prejudicam tanto sua própria aprendizagem, quanto o da sua equipe. Por isso, é preciso que parte da avaliação seja destinada aos testes individual e em equipe (TPi e TPe), bem como aos problemas da fase de aplicação. Essas avaliações não precisam, necessariamente, ter o grau de correção como critério avaliativo. Assim como em alguns trabalhos que utilizam os métodos Peer Instruction e Just-in-Time Teaching (e.g. ARAUJO; MAZUR, 2013), recomendamos que seja levado em conta o raciocínio demonstrado pelos alunos em suas respostas.

$\mathrm{Na}$ avaliação entre os colegas, indispensável para o bom andamento do método, o professor pode pedir que os estudantes, através de um questionário, atribuam pontuações aos colegas justificando-as com argumentos que demonstrem as contribuições deles à equipe. Outra alternativa é utilizar um questionário com afirmativas e opções que podem variar desde "discordo fortemente" a "concordo fortemente" (escala Likert). Michaelsen e Fink (2004) sugerem que os alunos, em suas avaliações, levem em consideração: a preparação do colega para a aula; a contribuição dele para as discussões e tarefas; o respeito por ele demonstrado frente às ideias dos outros membros da equipe; e também a flexibilidade de seu colega para lidar com discordâncias e conflitos. Além disso, os alunos podem destacar pontos positivos dos membros de sua equipe e aquilo que gostariam que eles melhorassem. Um exemplo de questionário para avaliação entre os colegas pode ser visto no Apêndice B.

\section{Estudos anteriores}

O TBL vem sendo aplicado em pelo menos 24 países e em todos os continentes, sendo que, desde a década de 80 do século XX, muitos trabalhos apontam diversos benefícios do seu uso em várias áreas do conhecimento (MICHAELSEN; SWEET; PARMELEE, 2008). Dentre elas, destacamos o ensino de Medicina, sobre o qual, desde 2001, há um número crescente de publicações (e.g. BURGESS; MCGREGOR; MELLIS, 2014; KOLES et al., 2010; THOMAS; BOWEN, 2011). O TBL também é tema de investigação em áreas como ensino de Enfermagem (e.g. CHENG et al., 2014), Fisiologia (e.g. SIMONSON, 2014), Direito (e.g. DANA, 2007), História da moda (e.g. BANNING; GAM, 2013) e Matemática (e.g. PATERSON; SNEDDON, 2011; NANES, 2014).

No ensino de Física, localizamos quatro artigos em uma busca pelas palavras-chave "Team-Based Learning" Physics, TBL Physics e "Aprendizagem Baseada em Equipes", nos seguintes mecanismos de busca: ERIC, Google Scholar, Portal de Periódicos da Capes e Web of Science. A procura foi feita a partir da data mais antiga disponível pelas plataformas até setembro de $2015^{15}$. Tais artigos são sintetizados no Quadro 1.

15 A pesquisa foi realizada no dia 21 de setembro de 2015. 
Em busca sistemática, revisando os títulos, palavras-chave e resumos, artigo a artigo, não localizamos a ocorrência de trabalhos sobre o TBL nos seguintes conceituados periódicos na área de Ensino de Física: Investigações em Ensino de Ciências (1996-2015), Experiências em Ensino de Ciências (2006-2015), Caderno Brasileiro de Ensino de Física (1984-2015), Ensaio (1999-2015), Revista Brasileira de Ensino de Física (1979-2015), Revista Brasileira de Pesquisa em Educação em Ciências (2001-2015), Revista de Ensino de Ciências e Engenharia (2010-2015), Revista Brasileira de Ensino de Ciências e Tecnologia (2008-2015), American Journal of Physics (1970-2015), Physical Review Special Topics - Physics Education Research (2005-2015), International Journal of Science Education (1979-2015), Journal of Research in Science Teaching (1970-2015), Research in Science Education (1971-2015), Science Education (1970-2015), Science \& Education (1992-2015), Enseñanza de las Ciencias (2010-2015), Latin American Journal of physics Education (2007-2015), Revista Electrónica de Enseñanza de las Ciencias (2004-2015), Revista Electrónica de Investigación em Educación em Ciencias (20062015) e Revista de Enseñanza de la Física (1985-2015).

Quadro 1 - Síntese dos artigos que usam TBL no ensino de Física.

\begin{tabular}{|c|c|c|c|}
\hline $\begin{array}{l}\text { Referência e pe- } \\
\text { riódico/evento }\end{array}$ & $\begin{array}{c}\text { Disciplina / } \\
\text { Conteúdo }\end{array}$ & $\begin{array}{c}\text { Nível de en- } \\
\text { sino }\end{array}$ & Foco do artigo \\
\hline $\begin{array}{l}\text { DEANTONIO et } \\
\text { al. }(2007) \\
\text { 37th ASEE/IEEE }\end{array}$ & $\begin{array}{c}\text { Laboratório } \\
\text { de Física }\end{array}$ & Graduação & $\begin{array}{l}\text { Descrição de uma aplicação do TBL em uma } \\
\text { disciplina de laboratório de Física e compara- } \\
\text { ção com o método baseado em investigação. }\end{array}$ \\
\hline $\begin{array}{l}\text { METOYER et } \\
\text { al. }(2009) \\
\text { Journal of Col- } \\
\text { lege Science } \\
\text { Teaching }\end{array}$ & $\begin{array}{l}\text { Física e Bi- } \\
\text { ologia }\end{array}$ & Graduação & $\begin{array}{l}\text { Descrição da estrutura de implementação do } \\
\text { TBL mostrando exemplos de suas diversas fa- } \\
\text { ses. } \\
\text { Avaliação do desempenho dos alunos e suas } \\
\text { impressões quanto ao uso do método em um } \\
\text { curso de Física conceitual. }\end{array}$ \\
\hline $\begin{array}{l}\text { PARDAMEAN } \\
\text { et al. }(2014) \\
\text { IFIP } 2014\end{array}$ & $\begin{array}{l}\text { Indução } \\
\text { Magnética }\end{array}$ & $\begin{array}{l}\text { Ensino Mé- } \\
\text { dio }\end{array}$ & $\begin{array}{l}\text { Descrição de uma implementação de vídeos e } \\
\text { do TBL no conteúdo de Indução Magnética. }\end{array}$ \\
\hline $\begin{array}{l}\text { PARAPPILLY; } \\
\text { SCHMIDT; RIT- } \\
\text { TER (2015) } \\
\text { European Journal } \\
\text { of Physics }\end{array}$ & $\begin{array}{l}\text { Física para } \\
\text { o mundo } \\
\text { moderno }\end{array}$ & Graduação & $\begin{array}{l}\text { Descrição da aplicação de uma versão modifi- } \\
\text { cada do TBL (utilizando o JiTT). } \\
\text { Avaliação do desempenho dos alunos em tes- } \\
\text { tes conceituais, das suas atitudes frente ao } \\
\text { método e da capacidade do TBL de estabele- } \\
\text { cer interações. }\end{array}$ \\
\hline
\end{tabular}

Os três primeiros artigos no Quadro 1 podem ser caracterizados como relatos de aplicação de uma proposta com avaliação empírica, enquanto o último é um artigo de pesquisa, apesar de não explicitar referenciais teórico e metodológico. 
DeAntonio et al. (2007) descrevem a aplicação do TBL em disciplinas de Física experimental da Universidade do Novo México (EUA) e comparam-na com aplicações do método de aprendizagem por investigação, anteriormente utilizado nas aulas de laboratório da universidade. Não são especificados detalhes sobre as turmas e conteúdos abordados. Os resultados são provenientes de observações e discussões com o professor assistente e tutores da disciplina. A partir da implementação do TBL, destacam-se três resultados: (i) os alunos se mostraram mais propensos a implementar e criar seus próprios experimentos; (ii) os estudantes de cursos de engenharia pareceram menos engajados com as atividades experimentais do que os alunos de Física, Biologia, Química, entre outros (os motivos não foram investigados no referido estudo); (iii) e um aumento na compreensão do processo experimental por parte dos alunos. As notas nos exames não tiveram variações com a mudança de método, porém os estudantes que tiveram aulas com o TBL recorreram muito menos à monitoria e tiveram maior frequência às aulas.

Pardamean et al. (2014) narram a implementação de vídeos e do TBL para o ensino de indução magnética em uma escola pública de Ensino Médio em Jacarta, Indonésia. Não são especificadas informações detalhadas sobre as turmas em que o método foi aplicado e nem sobre a metodologia de pesquisa. Os autores afirmam que o TBL ajuda os estudantes a desenvolverem habilidades para aprender de forma independente e para expressar suas ideias de forma coerente. No entanto, não é informado como os autores chegaram a tal inferência.

Um relato mais detalhado do uso do TBL no ensino de Física é feito por Metoyer et al. (2009), que apresentam a estrutura de implementação do TBL e mostram exemplos em contextos de cursos de Física, Química e Biologia em nível universitário em turmas que variam entre 30 a 100 alunos. Também mostram avaliações de desempenho e impressões de alunos de um curso de Física conceitual. Não são apresentados detalhes sobre os locais de aplicação. Segundo os autores, o emprego do TBL levou a uma série de mudanças positivas: aumento no sucesso acadêmico, melhor compreensão dos conceitos, aumento na participação em aula, maior nível de reflexão, maior interesse na disciplina e acréscimo da frequência dos estudantes. Em uma turma de Física conceitual, a pontuação em cada exame foi maior em média comparada aos exames aplicados em uma turma com aulas tradicionais. Também a taxa de evasão foi mais favorável à turma do TBL, pois houve cerca de 5\% (5 de 95 estudantes) de evasão no curso com TBL em comparação com 15\% (13 de 87 estudantes) em um curso com a abordagem tradicional.

Um estudo de Parappilly, Schmidt e Ritter (2015) descreve a aplicação do TBL, em conjunto com alguns elementos do método Just-in-Time Teaching, em uma turma de Física conceitual introdutória (Física para o mundo moderno) na Universidade de Flinders, Austrália. Os autores buscaram responder às seguintes questões: Quais são as atitudes dos estudantes em relação ao TBL? As interações entre os colegas realmente ocorrem no TBL? O TBL promove o aprendizado de conceitos de Física? Concluíram, através de dados coletados com um questi- 
onário, que os estudantes tiveram uma atitude positiva em relação ao TBL; análises das gravações das aulas em vídeo levaram os autores a verificar que os alunos realmente se engajaram nas interações; e, por meio de pré e pós testes, constataram ganhos de aprendizagem estatisticamente significativos.

Em síntese, existem poucos artigos sobre o uso do TBL no ensino de Física, que se constituem, essencialmente, em relatos de aplicações do método em determinados contextos, com resultados de aprendizagem e/ou atitudes dos alunos considerados positivos pelos autores. Tais estudos carecem de fundamentação teórica e metodológica.

Com o objetivo de avaliar a possibilidade de uso desse método em uma disciplina de Física Geral no contexto de uma universidade pública brasileira, foi feito um estudo exploratório em uma turma regular de eletromagnetismo da Universidade Federal do Rio Grande do Sul (OLIVEIRA, 2016). Resultados preliminares apontam que o TBL tem potencial para auxiliar na aprendizagem conceitual de Física e para desenvolver crenças de autoeficácia em aprender física e em trabalhar colaborativamente. Os estudantes responderam testes padronizados sobre conceitos básicos de eletromagnetismo, cujos ganhos médios normalizados da turma foram comparáveis aos derivados de aplicações com outros métodos ativos, inclusive na mesma disciplina e instituição, e superiores a resultados obtidos com métodos tradicionais de ensino. Através de questionários foram identificados os níveis de autoeficácia dos alunos, após constatada uma variação, foram realizadas entrevistas semiestruturadas, as quais indicaram que fatores relacionados ao método de ensino, como a resolução de questões conceituais e problemas em sala de aula e a interação prolongada com os membros da equipe, atuaram como potenciais fontes geradoras de autoeficácia em aprender física e em trabalhar colaborativamente, respectivamente.

\section{Considerações finais}

Entre os diversos desafios que se apresentam ao professor de Física em sua prática a falta de motivação e atitudes negativas em relação à Física, parecem onipresentes entre os alunos, o que termina influenciando diretamente nos resultados de aprendizagem alcançados. $\mathrm{Mu}-$ dar a sala de aula, tornando o aluno mais ativo, é uma das maneiras de alterar esse quadro.

Em específico, o uso do TBL, ao promover o desenvolvimento das equipes de aprendizagem, possibilita que os alunos alcancem melhores patamares no que tange a interação em grupo e a motivação para aprender. As estratégias do método, que vão desde a organização planejada das equipes até a avaliação entre os colegas, estimulam a interação e, consequentemente, a evolução das equipes. Essa característica especial do TBL possibilita o desenvolvimento de habilidades ligadas ao trabalho colaborativo, essenciais na sociedade contemporânea.

Em conjunto com suas potencialidades, a implementação de métodos ativos de ensino também traz desafios, comuns a inovações didáticas que tentem quebrar o paradigma de ensino tradicional. Além daqueles intrínsecos à preparação de materiais, possíveis obstáculos à implementação incluem a resistência do setor administrativo da instituição de ensino, dos colegas 
docentes e dos próprios alunos. Tais problemas são encontrados principalmente nas primeiras aplicações do método, mas, na medida em que se desejam resultados diferentes, é preciso superá-los. Para isso, o professor pode modificar sua prática gradativamente, não alterando todas as aulas de uma só vez.

Um dos maiores desafios que o professor que deseja utilizar o TBL pode encontrar é a falta de informações sobre como e o que fazer para aplicar o método, afinal, é escassa a quantidade de trabalhos e experiências na área da Física. O presente artigo pretende ser um primeiro passo para modificar este quadro em nível nacional.

Em termos de pesquisa em ensino de Física, faz-se necessário, ainda, entender as potencialidades e limitações do uso do método nesse contexto; investigar crenças e atitudes dos alunos frente ao método de ensino, analisar os impactos no ensino decorrentes da sua aplicação, compará-lo com outros métodos ativos e com o ensino tradicional e verificar a necessidade de possíveis adaptações do TBL ao contexto de ensino de Física brasileiro, tanto em nível universitário, quanto em nível médio.

Apesar das diversas vantagens que podem ser alcançadas com o TBL, obviamente não se trata de uma panaceia. Nossa intenção ao divulgá-lo é trazer uma alternativa que vem mostrando resultados positivos em outros contextos e que pode ser útil a professores de Física no Brasil. Frente aos desafios e necessidades de inovações na sala de aula de Física, a adoção de um método único de ensino, seja ele qual for, jamais conseguirá dar conta de todas as demandas que se apresentam no contexto escolar. A título de conclusão, ressaltamos a importância da pluralidade metodológica e da autonomia docente e esperamos, com esse trabalho, ter contribuído para divulgar um método de ensino que pode expandir o leque de possibilidades disponíveis para os professores que desejem transformar a sala de aula.

\section{Agradecimentos}

Agradecemos aos avaliadores pelas críticas e sugestões que contribuíram para o enriquecimento do presente trabalho.

\section{Referências}

ARAUJO, I. S.; MAZUR, E. Instrução pelos colegas e ensino sob medida: uma proposta para o engajamento dos alunos no processo de ensino-aprendizagem de Física. Caderno Brasileiro de Ensino de Física, v. 30, n. 2, p. 362-384, 2013.

BANNING, J.; GAM, H. J. Redesigning a fashion history course through Team-Based Learning. Clothing and Textiles Research Journal, v. 31, n. 3, p. 182-194, 2013.

BARROS, J. A. et al. Engajamento interativo no curso de Física I da UFJF. Revista Brasileira de Ensino de Física, v. 26, n. 1, p. 63-69, 2004. 
BARROSO, M. F. et al. A Evasão Universitária em Cursos de Física: desempenho dos estudantes e redução da evasão. In: SIMPÓSIO NACIONAL DE ENSINO DE FÍSICA, 15. 2003, Curitiba. Atas... Curitiba: CEFET-PR, 2003. p. 507-517.

BARROWS, H. S.; TAMBLYN R. M. Problem-based learning: an approach to medical education. New York: Springer, 1980.

BEICHNER, R. J. et al. The Student-Centered Activities for Large Enrollment Undergraduate Programs (SCALE-UP) Project. In: REDISH E. F.; COONEY, P. J. (Org.) Research-based reform of introductory physics. American Association of Physics Teacher, College Park, MD, 2007.

BERGMANN, J.; SAMS, A. Flip your Classroom: Reach Every Student in Every Class Every Day. Washington, DC: International Society for Technology in Education, 2012.

BIRMINGHAM, C.; MCCORD M. Group Process Research: Implications for Using Learning Groups. In: MICHAELSEN, L. K.; KNIGHT, A. B.; FINK, L. D. (Org.). Team-Based Learning: A Transformative Use of Small Groups in College Teaching. Sterling, VA: Stylus Publishing, LLC, 2004. p. 73-93.

BREWE et al. Toward equity through participation in Modeling Instruction in introductory university physics. Physics Review Special Topics - Physics Education Research, v. 6, n. 1, p. 010106-1-010106-2, 2010.

BURGESS, A. W.; MCGREGOR, D. M.; MELLIS, C. M. Applying established guidelines to team-based learning programs in medical schools: a systematic review. Academic Medicine: Journal of the Association of American Medical Colleges, v. 89, n. 4, p. 678-88, 2014.

CARVALHO, A. M. P. O ensino de ciências e a proposição de sequências de ensino investigativas. In: CARVALHO, A. M. P. (Org.) Ensino de Ciências por investigação: Condições para implementação em sala de aula. São Paulo: Cengage Learning, 2013. cap. 1. p. 1-20.

CHENG, C.-Y. et al. The effects of Team-Based Learning on learning behaviors in the maternal-child nursing course. Nurse education today, v. 34, n. 1, p. 25-30, 2014.

COTNER, S.; BAEPLER, P.; KELLERMAN, A. Scratch This! The IF-AT as a Technique for Stimulating Group Discussion and Exposing Misconceptions. Journal of College Science Teaching, March/April, p. 48-53, 2008.

CROUCH, C. H.; MAZUR, E. Peer Instruction: Ten years of experience and results. American Journal of Physics, v. 69, n. 9, p. 970, 2001.

DANA, S. W. Implementing Team-Based Learning in an Introduction to Law Course. Journal of Legal Studies Education, v. 24, n. 1, p. 59-108, 2007. 
DEANTONIO, M. et al. Work in progress-The use of team-based learning in an experimental physics lab. 37 th ASEE/IEEE Frontiers in Education Conference. Anais... p.13-14, 2007.

DUCH, B. Problem-Based Learning in Physics: the power of students teaching students. Journal of College Science Teaching, v. 25, n. 5, p. 326-239, 1996.

FINK, L. D. Beyond Small Groups: Harnessing the Extraordinary Power of Learning Teams. In: MICHAELSEN, L. K.; KNIGHT, A. B.; FINK, L. D. (Org.).Team-Based Learning: A Transformative Use of Small Groups in College Teaching. Sterling, VA: Stylus Publishing, LLC, 2004. p. 3-26.

FOUREZ, G. Crise no ensino de ciências? Investigações em Ensino de Ciências, v. 8, n. 2, p. 109-123, 2003.

HAKE, R. Interactive-engagement versus traditional methods: A six-thousand-student survey of mechanics test data for introductory physics courses. American Journal of Physics, v. 66, n. 1, p. 64-74, 1998.

HATTIE, J.; TIMPERLEY, H. The Power of Feedback. Review of Educational Research, v. 77, n. 1, p. 81-112, 2007.

HELLER, P. et al. Teaching problem solving through cooperative grouping. American Journal of Physics, v. 60, n. 7, p 627-644, 1992.

HELLER, P. et al. Cooperative Group Problem Solving in Physics. University of Minnesota, 1999. Disponível em: <http://www.ph12sics.umn.edu/groups/ph12sed>.

KOLES, P. G. et al. The impact of team-based learning on medical students' academic performance. Academic medicine : journal of the Association of American Medical Colleges, v. 85, n. 11, p. 1739-45, 2010.

LASRY, N.; MAZUR, E.; WATKINS, J. Peer instruction: From Harvard to the two-year college. American Journal of Physics, v. 76, n. 11, p. 1066, 2008.

LIMA JUNIOR, P. R. M. Evasão do ensino superior de Física segundo a tradição disposicionalista em sociologia da educação. 2013. 258 f. Tese (Doutorado Acadêmico em Ensino de Física) - Instituto de Física, Universidade Federal do Rio Grande do Sul (UFRGS), Porto Alegre.

LIMA JUNIOR, P. R. M.; OSTERMANN, F.; REZENDE, F. Análise dos condicionantes sociais da evasão e retenção em cursos de graduação em Física à luz da sociologia de Bourdieu. Revista Brasileira de Pesquisa em Educação em Ciências, v. 12, n. 1, p. 37-60, 2012.

LORENZO, M; CROUCH, C.; MAZUR, E. Reducing the gender gap in the physics classroom. American Journal of Physics, v. 74, n. 2, p. 118-122, 2006. 
LYMAN, F. The responsive classroom discussion. In: ANDERSON, A. S. (Org.). Mainstreaming digest. College Park, MD: University of Maryland College of Education, 1981.

LYMAN, F. Think-Pair Share: An expanding teaching technique: MMA-CIE. Cooperative News, v.1, p. 1-2, 1987.

MAZUR, E. Peer Instruction: a user's manual. Upper Saddle River: Prentice Hall, 1997.

METOYER, B. S. K. et al. Examples from the trenches: improving student learning in the sciences using Team-Based Learning. Journal of College Science Teaching, v. 43, n. 5, p. 4047, 2009.

MICHAELSEN, L. K. Getting Started with Team-Based Learning. In: MICHAELSEN, L. K.; KNIGHT, A. B.; FINK, L. D. (Org.). Team-Based Learning: a transformative use of small groups in college teaching. Sterling, VA: Stylus Publishing, LLC, 2004. p. 27-50.

MICHAELSEN, L. K.; FINK, L. D. Calculating Peer Evaluation Scores. In: MICHAELSEN, L. K.; KNIGHT, A. B.; FINK, L. D. (Org.). Team-Based Learning: A transformative use of small groups in college teaching. Sterling, VA: Stylus Publishing, LLC, 2004. p. 229-239.

MICHAELSEN, L. K.; KNIGHT, A. B.; FINK, L. D. Team-Based Learning: A transformative use of small groups in college teaching. Sterling, VA: Stylus Publishing, LLC, 2004.

MICHAELSEN, L. K.; SWEET, M.; PARMELEE D. X. (Org.). Team-Based Learning: Small-group learning's next big step. New Directions in Teaching and Learning. San Francisco, CA: Jossey-Bass, 2008.

MICHAELSEN, L.; SWEET, M. Team-based learning. New Directions for Teaching and Learning, n. 128, p. 41-51, 2011

MÜLLER, M. G. et al. Implementação do método de ensino Peer Instruction com o auxílio dos computadores do projeto "UCA" em aulas de Física do Ensino Médio. Caderno Brasileiro de Ensino de Física, v. 29, n. Especial 1, p. 491-524, 2012.

NANES, K. M. A modified approach to team-based learning in linear algebra courses. International Journal of Mathematical Education in Science and Technology, n. September, p. $1-12,2014$.

NOVAK, G. M.; PATTERSON, E. T.; GAVRIN, A. D.; CHRISTIAN, W. Just-in-time teaching: blending active learning with web technology. Upper Saddle River: Prentice Hall, 1999.

OAKLEY, B.; FELDER, R. M.; BRENT, R. Turning Student Groups into Effective Teams. Journal of student centered learning, v. 2, n. 1, p. 9-34, 2004.

OLIVEIRA, T. E. de. Aprendizagem de física, trabalho colaborativo e crenças de autoeficácia: um estudo de caso com o método Team-Based Learning em uma disciplina introdutória 
de eletromagnetismo. 2016. 209 f. Dissertação (Mestrado Acadêmico em Ensino de Física) Instituto de Física, Universidade Federal do Rio Grande do Sul (UFRGS), Porto Alegre.

OLIVEIRA, V.; VEIT, E. A.; ARAUJO, I. S. Relato de experiência com os métodos Ensino sob Medida (Just-in-Time Teaching) e Instrução pelos Colegas (Peer Instruction) para o Ensino de Tópicos de Eletromagnetismo no nível médio. Caderno Brasileiro de Ensino de Física, v. 32, n. 1, p. 180-206, 2015.

PARAPPILLY M.; SCHMIDT, S.; RITTER, S. Ready to learn physics: a team-based learning model for first year university. European Journal of Physics, v. 36, n. 5, p. 1-13, 2015.

PARDAMEAN, B. et al. Enhancing the use of digital model with Team-Based Learning approach in science teaching. In: International Federation for Information Processing, 2014. Anais... p.267-276, 2014.

PASSOS, F. G. dos et al. Diagnóstico sobre a reprovação nas disciplinas básicas dos cursos de engenharia da UNIVASF. In: CONGRESSO BRASILEIRO DE EDUCAÇÃO EM ENGENHARIA, XXXV, 2007, Curitiba. Anais... Curitiba, 2007.

PATERSON, J.; SNEDDON, J. Conversations about curriculum change: mathematical thinking and team-based learning in a discrete mathematics course. International Journal of Mathematical Education in Science and Technology, v. 42, n. 7, p. 879-889, 2011.

RUDOLPH, A. L. et al. Introduction of interactive learning into French university physics classrooms. Physical Review Special Topics - Physics Education Research, v. 10, n. 1, p. 1$18,2014$.

SILVA, B. V. C.; MARTINS, A. F. P. Júri simulado: um uso da história e filosofia da ciência no ensino de óptica. Física na Escola, v. 10, n. 1, p. 17-20, 2009.

SILVEIRA, F. L.; MOREIRA, M. A.; AXT, R. Habilidad en preguntas conceptuales y en resolución de problemas de Física. Enseñanza de las Ciencias, v. 10, n. 1, p. 58-62, 1992.

SIMONSON, S. R. Making students do the thinking: team-based learning in a laboratory course. AJP: Advances in Physiology Education, v. 38, n. 1, p. 49-55, 2014.

STEAD, D. R. A review of the one-minute paper. Active Learning in Higher Education, v. 6, n. 2, p. 118-131, 2005.

SWEET, M. S.; MICHAELSEN, L. K.; WRIGHT, C. M. Simultaneous report: A reliable method to stimulate class discussion. Decision Sciences Journal of Innovative Education, v. 6, n. 2, p. 483-487, 2008. 
THOMAS, P. A; BOWEN, C. W.A controlled trial of team-based learning in an ambulatory medicine clerkship for medical students. Teaching and learning in medicine, v. 23, n. 1, p. 31-6, 2011.

VIEIRA, R.; MELO, V.; BERNARDO, J. O Júri Simulado como recurso didático para promover argumentações na formação de professores de Física: o problema do "gato". Revista Ensaio, v. 16, n. 3, p. 203-225, 2014.

WATKINS, B. J.; MAZUR, E. Retaining Students in Science, Technology, Engineering, and Mathematics (STEM) Majors. Journal of College Science Teaching, v. 24, n. 5, p. 36-41, 2013.

WATSON, W. E.; MICHAELSEN, L. K.; SHARP, W. Member competence, group interaction, and group decision making: A longitudinal study. Journal of Applied Psychology, v. 76, n. 6, p. 803-809, 1991.

\section{Apêndice A}

Neste apêndice, apresentamos um exemplo de questionário para definição das equipes.

\section{Conhecendo você! 16}

Nome completo:

Idade:

Sexo: ( ) masculino ( ) feminino

Você concluiu algum curso técnico ou outra graduação? Se sim, qual(is)?

Você possui experiência profissional no mercado de trabalho? Especifique.

Você exerce, ou já exerceu, alguma atividade de monitoria e/ou iniciação científica na universidade? Qual?

Você possui experiência de uso de grupos em sala de aula?

( ) sim, muita.

( ) sim, pouca.

( ) não.

Quais os aspectos que você julga fundamentais para que o trabalho em grupo se desenvolva bem?

Você participa de grupos de estudos? Se sim, com que frequência? Descrever brevemente alguma experiência que tenha tido.

Você é parente, amigo(a) de longa data, namorado(a) ou similar de alguém nesta turma?

\footnotetext{
16 Adaptado de OAKLEY, FELDER e BRENT (2004)
} 
Com que frequência você costuma estudar na semana?

( ) 1 dia por semana.

( ) 2 dias por semana.

( ) 3 dias por semana.

( ) 4 dias por semana.

( ) 5 dias por semana.

( ) todos os dias da semana.

( ) apenas antes das provas.

Você já cursou mais de uma vez alguma disciplina do seu atual curso? Se sim, qual(is)?

Tem algo sobre você que é, provavelmente, um diferencial perante os demais colegas? (por exemplo, uma experiência diferente, um hobby, alguma habilidade ou interesse)

Por que você decidiu fazer o curso de Física?

Você julga que possuí alguma(s) dificuldade(s) para aprender Física? Se sim, qual(is)?

Você tem mais afinidade em que área da Física? (Física teórica, Física experimental, ensino de Física, etc.)

O que você pretende fazer depois que se formar?

Este espaço está livre para que escreva qualquer coisa que ache necessário sobre você (opcional).

\section{Apêndice B}

Neste apêndice, apresentamos um exemplo de questionário para a avaliação entre os colegas.

\section{Avaliação dos colegas de equipe}

Nome:

Para avaliar os trabalhos realizados em equipe nesta disciplina, contamos com sua avaliação sobre o seu próprio trabalho e o de seus colegas de equipe. Suas respostas servirão para auxiliar o professor no processo avaliativo, mas não definirão, necessariamente, as notas recebidas pelos alunos, incluindo a sua própria. Procure responder da forma mais sincera que puder. Suas respostas serão mantidas anônimas.

Marque a alternativa que melhor expressa seu nível de concordância.

CF: Concordo Fortemente

C: Concordo

I: Indeciso (tente ao máximo evitar essa alternativa)

D: Discordo

DF: Discordo Fortemente 


\begin{tabular}{|c|c|c|c|c|c|}
\hline Nome do colega 1: & $\mathbf{C F}$ & $\mathbf{C}$ & I & D & DF \\
\hline $\begin{array}{l}\text { 1) Eu percebo que o colega está vindo preparado para a aula, ou } \\
\text { seja, está realizando as Tarefas de Leitura requeridas pelo profes- } \\
\text { sor. }\end{array}$ & & & & & \\
\hline $\begin{array}{l}\text { 2) O colega contribuiu de forma positiva para as discussões em } \\
\text { grupo. }\end{array}$ & & & & & \\
\hline $\begin{array}{l}\text { 3) O colega respeitou as ideias e opiniões dos outros membros da } \\
\text { equipe. }\end{array}$ & & & & & \\
\hline $\begin{array}{l}\text { 4) O colega não encorajou a contribuição de outros membros da } \\
\text { equipe. }\end{array}$ & & & & & \\
\hline $\begin{array}{l}\text { 5) O colega foi flexível quando aconteceu alguma discordância ou } \\
\text { conflito de opiniões na equipe. }\end{array}$ & & & & & \\
\hline $\begin{array}{l}\text { 6) Penso que meu colega não aprendeu a maior parte dos concei- } \\
\text { tos de Física estudados. }\end{array}$ & & & & & \\
\hline $\begin{array}{l}\text { 7) O colega aparentou estar pouco confiante e desmotivado para } \\
\text { realizar as atividades requeridas pela disciplina. }\end{array}$ & & & & & \\
\hline $\begin{array}{l}\text { 8) Acredito que meu colega não é capaz de resolver sozinho a } \\
\text { maior parte dos problemas referentes aos tópicos estudados. }\end{array}$ & & & & & \\
\hline $\begin{array}{l}\text { 9) Acredito que meu colega não é capaz de resolver em equipe a } \\
\text { maior parte dos problemas referentes aos tópicos estudados. }\end{array}$ & & & & & \\
\hline $\begin{array}{l}\text { 10) Julgo que o colega, em diversos momentos, contribuiu com } \\
\text { suas explicações para o aprendizado dos colegas de grupo. }\end{array}$ & & & & & \\
\hline $\begin{array}{l}\text { 11) Acredito que, em diversos momentos, o colega foi capaz de } \\
\text { convencer os outros membros da equipe de sua resposta, indepen- } \\
\text { dente se ela estivesse correta ou não. }\end{array}$ & & & & & \\
\hline \multicolumn{6}{|c|}{$\begin{array}{l}\text { Se você julgar necessário, deixe um comentário dizendo aquilo que você destacaria como pontos } \\
\text { positivos do seu colega durante esta área e/ou o que você gostaria que seu colega melhorasse } \\
\text { para as próximas aulas. }\end{array}$} \\
\hline
\end{tabular}

Com base em suas respostas aos itens deste questionário, atribua uma nota de 0 a 10 para você e para cada um de seus colegas de equipe: 


\section{Pontuação}

Seu Nome:

Nome do colega 1:

Nome do colega 2:

Nome do colega 3:

Nome do colega 4:

Use este espaço para fazer qualquer comentário que julgar pertinente. 